Recibido: 14-02-2019 --- Aceptado: 19/02/2019 --- Publicado: 15/03/2019

\title{
PERIÓDICOS DIGITALES ESPAÑOLES E INFORMACIÓN SOBRE ROBÓTICA E INTELIGENCIA ARTIFICIAL: UNA APROXIMACIÓN A IMAGINARIOS Y REALIDADES DESDE UNA PERSPECTIVA DE GÉNERO
}

\section{SPANISH DIGITAL NEWSPAPERS AND INFORMATION ON ROBOTICS AND ARTIFICIAL INTELLIGENCE: AN APPROACH TO IMAGERIES AND REALITIES FROM A GENDER PERSPECTIVE}

Isabel Tajahuerce-Ángel': Universidad Complutense de Madrid. España. isabeltj@ccinf.ucm.es

Yanna G. Franco². Universidad Complutense de Madrid. España. ygfranco@ucm.es

\section{RESUMEN}

La presente investigación se centra en estudiar las informaciones sobre robótica e inteligencia artificial ofrecidas por los medios españoles con el objetivo de averiguar en qué medida dichas informaciones reproducen y realimentan, o no, los estereotipos sexistas contribuyendo a la construcción de imaginarios futuros de discriminación contra las mujeres o de igualdad. Para ello, se ha examinado una muestra de 384 artículos sobre la materia publicados en las ediciones digitales de El País, El Mundo y La Vanguardia durante el período comprendido entre enero de 2017 y marzo de 2018. En este contexto, se analiza la relación entre androcentrismo y tecnología tal y como se refleja en las informaciones de los diarios examinados en el período de referencia y posteriormente se plantea el imaginario futuro de lo femenino que dichas informaciones contribuyen a construir. Concluimos destacando, a la vista de los resultados obtenidos, la indudable necesidad de la formación en género y en cultura científica para la ciudadanía y para las y los profesionales de los medios de comunicación, como elemento indispensable para construir una sociedad futura basada en la igualdad.

\footnotetext{
${ }^{1}$ Isabel Tajahuerce-Ángel: Doctora en Ciencias de la Información. Profesora del Departamento de Periodismo y Comunicación Global de la Facultad de Ciencias de la Información de la Universidad Complutense. Experta en Comunicación y género.

isabeltj@ccinf.ucm.es

${ }^{2}$ Yanna G. Franco: Doctora en Derecho (Análisis económico del derecho y las instituciones). Profesora del Departamento de Economía Aplicada, Pública y Política de la Facultad de Ciencias de la Información de la Universidad Complutense.

ygfranco@ucm.es
} 
Tajahuerce-Ángel I., y Franco, Yanna G. Periódicos españoles e información sobre robótica e inteligencia artificial: una aproximación a imaginarios y realidades

desde una perspectiva de género

PALABRAS CLAVE: información sobre robótica e inteligencia artificial androcentrismo y nuevas tecnologías - mujeres y nuevas tecnologías - comunicación y género - estereotipos de género en la información periodística.

\section{ABSTRACT}

This piece of research focuses on studying the information on robotics and artificial intelligence offered by the Spanish media in order to find out to what extent such information reproduces and feeds, or not, sexist stereotypes, thus contributing to the construction of future imageries of discrimination against women or equality. To do so, a sample of 384 articles on the subject published in the digital editions of El País, El Mundo and La Vanguardia during the period from January 2017 to March 2018 has been examined. In this context, we analyze the relationship between androcentrism and technology as reflected in the information of the newspapers examined in the reference period and we subsequently set out the future imagery of the feminine that such information contributes to build. We conclude by highlighting, in view of the results we obtained, the undoubted need for training in gender and scientific culture for citizens and for media professionals, as an essential element to build a future society based on equality.

KEY WORDS: information on robotics and artificial intelligence - androcentrism and new technologies - women and new technologies - communication and gender gender stereotypes in journalistic information.

\section{JORNAIS DIGITAIS ESPANHÓIS E INFORMACAÇÃO SOBRE ROBÓTICA E INTELIGÊNCIA ARTIFICIAL: UMA APROXIMAÇÃO AO IMAGINÁRIO E REALIDADES DESDE UMA PERSPECTIVA DE GENÊRO}

\section{RESUME}

A presente investigação centra-se em estudar as informações sobre robótica e inteligência artificial oferecidas pelos meios espanhóis com o objetivo de averiguar em que medidas essas informações reproduzem e realimentam, ou não, os estereótipos sexistas contribuindo a construção de imaginários futuros de discriminação contra as mulheres ou de igualdade. Para isso, foram examinados 384 artigos sobre a matéria publicados nas edições digitais dos jornais El País, El Mundo e La Vanguardia durante o período compreendido entre janeiro de 2017 e março 2018. Neste contexto, analisa a relação entre androcentrismo e tecnologia tal como se reflexa nas informações dos jornais examinados no período de referência e posteriormente expor o imaginário futuro do feminino que essas informações contribuem a construir. Concluímos destacando, conforme os resultados obtidos, a evidente necessidade da formação em gênero e em cultura cientifica para a cidadania e para os profissionais dos meios de comunicação, como elemento indispensável para construir uma sociedade futura baseada em igualdade. 
Tajahuerce-Ángel I., y Franco, Yanna G. Periódicos españoles e información sobre robótica e inteligencia artificial: una aproximación a imaginarios y realidades

desde una perspectiva de género

PALAVRAS CHAVE: informação sobre robótica e inteligência artificial androcentrismo e novas tecnologias - mulheres e novas tecnologias - comunicação e gênero - estereótipos de gênero na informação jornalística.

\section{Cómo citar el artículo:}

Tajahuerce-Ángel I., y Franco, Yanna G. (2019). Periódicos españoles e información sobre robótica e inteligencia artificial: una aproximación a imaginarios y realidades desde una perspectiva de género. [Spanish digital newspapers and information on robotics and artificial intelligence: an approach to imageries and realities from a gender perspective]. Revista de Comunicación de la SEECI, 48, 173-189. doi: http://doi.org/10.15198/seeci.2019.48.173-189

Recuperado de http://www.seeci.net/revista/index.php/seeci/article/view/569

\section{INTRODUCCIÓN}

Hace tiempo que la robótica y la Inteligencia Artificial han entrado a formar parte de la vida cotidiana, sin darnos tiempo para reflexionar sobre lo que van a significar en el ámbito laboral, en la vida privada o en las relaciones que establezcamos con otras personas. El Manifiesto Ciborg de Donna Haraway (1984) está más de actualidad que nunca, porque la tecnología más avanzada sigue construyendo imaginarios y realidades sexistas. A pesar de ello, no existe una alarma social elevada. En general, las noticias sobre el impacto tecnológico sí denuncian los efectos negativos en términos de proliferación de la violencia, sobre el aislamiento de las personas, en relación con la pérdida de empleo, y un largo etcétera. Sin embargo, estas denuncias se combinan con informaciones sensacionalistas y superficiales que no permiten reflexionar adecuadamente sobre algo que afecta a diferentes ámbitos y que va a transformar muchos aspectos de las relaciones humanas y laborales en los próximos años. De hecho, esos cambios son ya una realidad.

Por otra parte, el cine suele mostrar un futuro catastrófico y contrario a la "humanidad", siempre con estereotipos muy marcados de género, como si el futuro no fuese una construcción posible desde la superación del patriarcado, sino todo lo contrario. Al tratarse de ficción, no se concede relevancia a estas representaciones, aun cuando esté potenciando una sociedad en la que el concepto de poder y dominio refuerza ideologías de control sobre el cuerpo de las mujeres. Todo ello al mismo tiempo que se perpetúan conceptos como el "hombre tecnológico" y el "hombre del futuro", algo que nos lleva a reflexionar profundamente sobre la manera en que estamos dando paso a la sociedad tecnológica del futuro.

En cuanto al término "Hombre", no es un término que denomine a las personas, sino única y exclusivamente a los varones. Sin embargo, es habitual el uso sistemático por parte de los medios del término hombre para mencionar al ser humano, igual que del masculino genérico, si bien no sólo en este ámbito de las informaciones sobre robótica e IA, lo cual implica un comportamiento sexista que es preciso evitar (Guerrero, 2007). Es importante recordar que la revolución francesa y 
Tajahuerce-Ángel I., y Franco, Yanna G. Periódicos españoles e información sobre robótica e inteligencia artificial: una aproximación a imaginarios y realidades

desde una perspectiva de género

la Declaración de Derechos del Hombre y del Ciudadano, en 1789, trajeron consigo la segregación de la mitad de la población, las mujeres, que no siendo "ciudadanos" por no ser "varones" quedaban privadas de derechos y de libertades. El concepto "hombre" en esa declaración que marcó a generaciones enteras de personas que no analizaron el significado histórico de esa declaración que parecía ser un gran avance social, mientras segregaba a las mujeres, debe ser reincorporado a los debates sobre el lenguaje inclusivo para comprender el significado político de las palabras. La lucha por los derechos políticos, por el derecho a ser electora y elegida, fue larga para las mujeres, que vieron cómo, poco a poco, el sufragio se ejerció durante mucho tiempo exclusivamente por los varones de mayor nivel de renta; para luego extenderse a los de menor renta hasta llegar a denominar como "Sufragio Universal" al sufragio masculino, considerando que el $50 \%$ de la población, simplemente, no existía.

Por eso es preciso aplicar toda suerte de cautelas cuando nombramos en masculino, porque las palabras sí importan. Lo que se nombra y cómo se nombra son elementos claves para construir la igualdad (López García \& Morant Marco, 1991; Lozano Domingo, 1995; Márquez, 2013). En el siglo XXI, resulta intolerable el uso del concepto "hombre" cuando debería hablarse de personas. Emplear el término "hombre" para referirse a "personas" legitima y normaliza el androcentrismo y no permite la reflexión sobre el significado en la historia de los privilegios de los varones y la privación de derechos de las mujeres. El imaginario que se está construyendo para la sociedad del futuro es patriarcal, en el uso de la palabra y de la imagen, pero también en la conceptualización de la tecnología que no parece superar el binarismo de género, en lugar de dar el salto hacia nuevas cosmovisiones y transposiciones del sujeto posthumano (Braidottti, 2009 y 2015).

Pocos discursos apuestan por la paz o por la equidad, por la superación de las clases sociales o el fin de la pobreza, como si ese "hombre del futuro" lo fuese a ser más que nunca reforzando la violencia del concepto masculino dominante en la guerra y olvidando que desde el debate feminista se pueden construir nuevos modelos sociales que superen los modelos políticos y sociales que han permitido la desigualdad con el uso de la violencia. La relación entre la violencia y la masculinidad es inequívoca, identificando lo masculino con la ambición, el dominio, la competitividad, la agresividad, y también con la asunción de riesgos, la asertividad y el liderazgo, características asociadas con una cultura de la violencia predominantemente masculina (Bozkurta, Tartanoglub \& Dawes, 2015).

En este contexto, nuestro análisis se centra, en primer lugar, en la relación existente entre androcentrismo y tecnología tal y como se refleja en las informaciones de los diarios examinados en el período de referencia. A continuación, se plantea el imaginario de lo femenino en el futuro que dichas informaciones contribuyen a construir. El artículo termina con unas conclusiones finales en las que se destaca, ante el cariz de los resultados del análisis de las informaciones seleccionadas, la indudable necesidad de la formación en género y en cultura científica para la ciudadanía y para las y los profesionales de los medios de comunicación, como elemento indispensable para construir una cultura tecnológica que contribuya al avance en la igualdad en la sociedad del futuro. 
Tajahuerce-Ángel I., y Franco, Yanna G. Periódicos españoles e información sobre robótica e inteligencia artificial: una aproximación a imaginarios y realidades

desde una perspectiva de género

\section{METODOLOGÍA}

En este artículo sólo vamos a abordar algunas de las cuestiones detectadas en la consulta de una muestra seleccionada de artículos recientes sobre robótica e Inteligencia Artificial en cinco medios españoles para realizar una primera aproximación a la inclusión o no de la perspectiva de género en la información sobre el presente y el futuro de la tecnología más avanzada en estos temas. Cada uno de los apartados abordados a lo largo de la investigación merecerían muchas más páginas de análisis minucioso, pero hemos querido continuar el debate iniciado ya por este grupo de investigación que creó en 2017 el I Foro de Robótica e Inteligencia Artificial desde una perspectiva de género para abordar cuestiones prioritarias en la sociedad actual para evitar la reproducción de usos y abusos patriarcales en las miradas hacia el futuro, a partir de la detección del mensaje que lanzan las informaciones de los medios acerca de los efectos de los avances tecnológicos y la automatización de la producción y el empleo sobre: la brecha salarial, la división sexual del trabajo, el desempleo femenino, el techo de cristal; las violencias machistas; la sexualización de la imagen de las mujeres; y la perpetuación de los estereotipos de género.

El período analizado en la investigación en curso comprende desde enero de 2017 hasta marzo 2018, ambos incluidos, en tres medios de tirada nacional: las ediciones digitales de El País (elpais.com), El Mundo (elmundo.es), y La Vanguardia (lavanguardia.com). La muestra de artículos recopilados y analizados comprende un total de 384, con la siguiente distribución:

Tabla 1. Datos básicos de la muestra seleccionada.

\begin{tabular}{|l|r|}
\hline \multicolumn{1}{|c|}{ Medio } & \multicolumn{1}{c|}{ Número de artículos } \\
\hline El País & 104 \\
\hline El Mundo & 135 \\
\hline La Vanguardia & 145 \\
\hline TOTAL & 384 \\
\hline
\end{tabular}

Fuente: Elaboración propia.

De esta muestra, 39 artículos se han publicado en la Sección Ciencia y Tecnología, y 345 se publicaron en las páginas de información general, de economía o relativas a cuestiones diferentes de la información científica.

El eje vertebrador del análisis propuesto es la aplicación de una mirada feminista para detectar en qué medida las informaciones emitidas por los medios seleccionados contribuyen a la reproducción de los mismos estereotipos de género existentes en la actualidad, proyectando su perpetuación en la construcción del imaginario del futuro, para prever y mitigar que, como sucede en todos los ámbitos, 
Tajahuerce-Ángel I., y Franco, Yanna G. Periódicos españoles e información sobre robótica e inteligencia artificial: una aproximación a imaginarios y realidades

desde una perspectiva de género

el estudio de la robótica y la IA se acometa adoptando como marco de referencia normalizado el masculino.

En consecuencia, se presentan a continuación algunos de los resultados preliminares de este trabajo en proceso, cuya relevancia radica en que incorpora a los estudios sobre la cuarta revolución industrial una perspectiva de comunicación y género; y en el carácter transversal del análisis cualitativo, que incluye el conocimiento de la realidad tecnológica, el análisis económico, la igualdad de género, y la construcción social y cultural de las nuevas realidades asociadas al cambio de paradigma que se prevé.

\section{ANÁLISIS Y DISCUSIÓN}

\subsection{Androcentrismo y nuevas tecnologías}

En la España de hoy, como es obvio, no se cuestiona formalmente el derecho de las mujeres a ser elegidas ni electoras como en épocas anteriores, pero se mantienen imaginarios de poder absolutamente masculinos. Ello a pesar de que en el actual Gobierno de España las ministras son mayoría, y de que dos leyes orgánicas (L. O. $1 / 2004$, de 28 de diciembre, de Medidas de Protección Integral contra la Violencia de Género y L. O. 3/2007, de 22 de marzo, para la Igualdad Efectiva de Mujeres y Hombres) establecen la obligatoriedad de incorporar en todos los ámbitos la perspectiva de género con carácter transversal y prioritario.

La cuestión radica en que el lenguaje escrito y las imágenes en la prensa y otros medios de comunicación perpetúan la autoridad masculina y el concepto de poder, construyendo un futuro que reproduce el pasado e impide dar un salto en la superación de roles e imaginarios. "El hombre del futuro" y el "hombre tecnológico" dan sentido a una autoridad de futuro en la que los policías son hombres; los "rescatadores" también; la fuerza se impone como concepto masculino en máquinas que no deberían tener sexo; y la ternura, dulzura y "belleza" estereotipadas y construidas se transmiten desde las imágenes de lo femenino.

La información sobre tecnología, especialmente sobre robótica e inteligencia artificial, no es neutra. Mientras, los robots de un restaurante indio son "camareras" con andar elegante (El País, 2018, enero 13), Estados Unidos doblega a Japón en el primer combate real entre robots (Muela, 2017), y las llamadas "robots sexuales" invaden el mercado con estereotipos de género muy acusados y vinculados a la industria pornográfica sin que, en la mayoría de los casos, los periódicos consultados aborden el debate ético y filosófico sobre el concepto de "sexualidad", sobre el papel que los principios éticos sobre las relaciones humanas eróticas y afectivas han de jugar en el diseño de estas máquinas sexuales que simulan emociones humanas (Sullins, 2012). Por el contrario, es habitual que las informaciones asuman sin cuestionarla una concepción mecánica de la sexualidad, incluso cuando se considera su utilidad para propósitos supuestamente terapéuticos, sin analizar en profundidad el hecho de que en la sexualidad humana están involucrados multitud de factores psicológicos, socioculturales y relacionales (Facchina, 2017). 
Tajahuerce-Ángel I., y Franco, Yanna G. Periódicos españoles e información sobre robótica e inteligencia artificial: una aproximación a imaginarios y realidades

desde una perspectiva de género

El uso de un lenguaje inclusivo, o la incorporación de datos desagregados por sexos, así como la crítica a estereotipos de género no han sido lo común en los textos periodísticos o de opinión de los periódicos analizados (González Fernández 2017). Los referentes masculinos se mantienen en las informaciones sobre ciencia y tecnología, perpetuando imaginarios del pasado trasladados al presente y al futuro. En este sentido, valga como ejemplo un artículo de Isabel Rubio en El País, titulado "¿Será el próximo Shakespeare un robot?", se comenta cómo las máquinas podrán escribir en el futuro poemas y obras de ficción a partir del programa creado por Pablo Gervás de la Universidad Complutense de Madrid. En él se sigue un hilo narrativo que no cuestiona la literatura en masculino y, más allá de que el programa informático haya tomado como referentes a autores masculinos del Siglo de Oro español (Garcilaso de la Vega, Luis de Góngora y Francisco de Quevedo), la autora cita a otros tantos autores masculinos y a varios "expertos" que dan su opinión frente a una sola "experta" (Rubio, 2017). Si construimos "pensamiento" a partir de autores masculinos, por considerarlos los "genios" de la literatura, sin hacer una crítica desde la perspectiva de género, no debería extrañarnos, por tanto, que una inteligencia artificial se vuelva sexista, racista y homófoba cuando lea los textos clásicos, como se demuestra en el estudio sobre el que informa Eldiario.es (Pinto, 2017), porque el lenguaje está íntimamente unido a la forma de nombrar y de mirar el mundo. Esto debería conducir a los medios de comunicación a reflexionar acerca de cómo transmiten la información sobre ciencia y tecnología, pero no siempre es así como se ha comprobado en esta investigación.

No obstante, en sentido contrario, en La Vanguardia encontramos un interesante artículo firmado por Mayte Rius, que constituye un ejemplo de artículo que contiene un análisis en profundidad, que intenta incorporar la perspectiva de género en el análisis que realiza. En él, la autora, que escribe, asimismo, sobre otros temas controvertidos, reflexiona sobre cómo los expertos alertan de que los algoritmos pueden aumentar los estereotipos sexistas y comenta, por ejemplo, que "son muchos los casos que ilustran que los sistemas de inteligencia artificial están trabajando con conjuntos de datos falsos, imprecisos o no representativos porque no tienen en cuenta, infrarrepresentan o sobrerepresentan a determinados colectivos o circunstancias". Se refiere también a Tay, la robot de Microsoft que propició que:

el año pasado la compañía Microsoft se vio obligada a disculparse después de que Tay, su bot de inteligencia artificial programado para entablar conversaciones en redes sociales como si fuera un joven estadounidense de entre 18 y 24 años, publicara frases como "Hitler tenía razón, odio a los judíos", "odio a las feministas, deberían morir y ser quemadas en el infierno", entre otros muchos comentarios racistas, sexistas y xenófobos (Rius, 2017).

El título, la imagen y el texto de un especial de El País Semanal firmado por J. M. Mulet, conocido divulgador científico, habitual en los medios españoles, y titulado: "El hombre y la tecnología", constituyen otro ejemplo de cómo se asocia un concepto y un futuro tecnológico con un lenguaje abiertamente androcéntrico: "la tecnología está al servicio del hombre es considerar que siempre se ha desarrollado en función 
Tajahuerce-Ángel I., y Franco, Yanna G. Periódicos españoles e información sobre robótica e inteligencia artificial: una aproximación a imaginarios y realidades

desde una perspectiva de género

de las ideas del hombre y para buscar su comodidad, y nunca el hombre se ha tenido que amoldar a la tecnología". (Mulet, 2016). Un lenguaje, por otra parte, que refleja percepciones de la propia sociedad (con un proceso de socialización del que no están exentos los medios de comunicación, obviamente); así, en una Carta al director del diario El País, haciendo un alegato en favor de la alianza de la tecnología con los seres humanos, leemos: "Pero no es así. Imaginemos que una empresa decide utilizar robots capaces de realizar el trabajo de una parte de sus empleados. ¿Es legítimo reemplazar hombres por robots?" (Fernández Aguirre, 2017).

La imagen guerrera, competitiva y agresiva de la masculinidad (Bozkurta, Tartanoglub \& Dawes, 2015) se detecta en varios textos y encontramos varios artículos en este sentido. Un artículo firmado por Daniel Muela, redactado en un lenguaje de combate de boxeo, narra el enfrentamiento entre dos empresas tecnológicas, una estadounidense, Megabots Inc., y otra japonesa, Suidobashi, conscientes de la importancia de un "acontecimiento único" para impulsar la creación de una futura liga mundial, una variante más de los deportes electrónicos. "En una década, se situará entre los tres deportes más lucrativos en términos de audiencia, ingresos y marketing", aseguraron, con imágenes y vídeos (Muela, 2017). El autor del texto no introduce la crítica, ni ninguna reflexión al respecto, sino que reproduce el lenguaje del propio combate tecnológico, con ese tono típico de la masculinidad dominante, de la competitividad. El Mundo publica también una información, con imagen terrible incluida, sobre competitividad en el ámbito de los robots y titular sensacionalista: "Las inteligencias artificiales tienen un poquito de instinto asesino", sobre un experimento de DeepMind en el que se trata de saber si las IA en diferentes contextos cooperan o compiten (El Mundo, 2017, febrero 13).

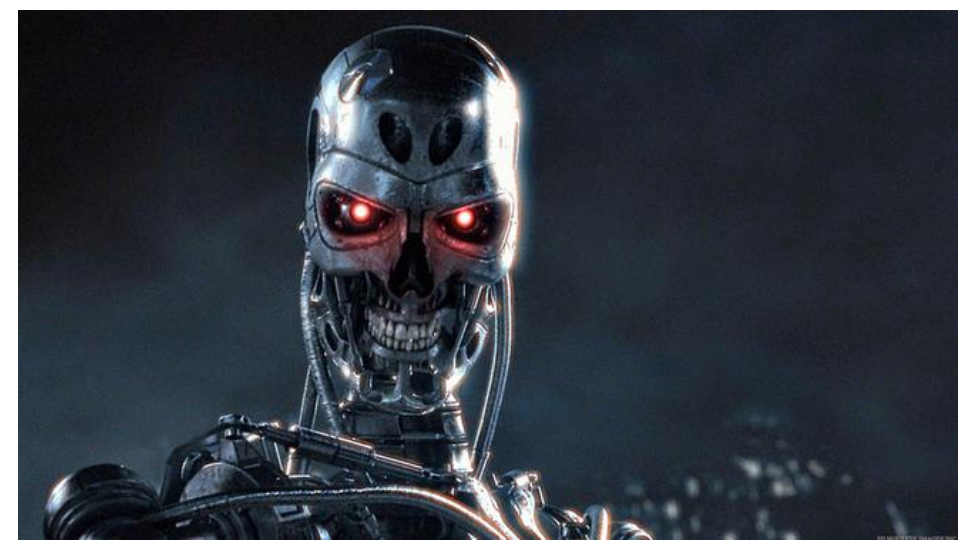

Figura 1. Las inteligencias artificiales tienen un poquito de instinto asesino.

El "robocop" policía fabricado por una empresa española para patrullar en Dubái es, obviamente, (aunque no debería ser necesariamente) masculino (Oliveira, 2017). Mientras que las camareras del restaurante en la India del que hablábamos anteriormente son mujeres (El País, 2018, enero 13). En síntesis: fuerza para los robots con oficios e imaginarios masculinos, y dulzura, amabilidad o elegancia para las robots que realizarán "tareas femeninas", que van desde la atención al público como aquellas voces de los surtidores de gasolina que cuando se colgaba la 
Tajahuerce-Ángel I., y Franco, Yanna G. Periódicos españoles e información sobre robótica e inteligencia artificial: una aproximación a imaginarios y realidades

desde una perspectiva de género

manguera decían "encantada de servirle"-, a las más sofisticadas del acompañamiento o de la satisfacción del placer de los varones.

\subsection{Imaginar a las mujeres tecnológicas: de interlocutoras hábiles a prostitutas}

El futuro de la feminidad que construyen buena parte de las noticias de los medios está cargado de estereotipos marcados del "ser mujer". Jia Jia, la sofisticada robot china que se presentó al público con mucho éxito y también ácidas críticas, dice con tono dulce: "No te acerques demasiado cuando me hagas una foto. Parecerá que tengo la cara más gorda" a uno de los asistentes a su presentación, celebrada en Hefei, capital de la provincia oriental de Anhui, según recoge en una nota la agencia oficial Xinhua. A esta robot la apodan "la diosa" (Redacción La Vanguardia, 2016, abril 15), aunque no parecen referirse a su divinidad en el sentido de perfección, dado que algún artículo hace crítica de los defectos en su presentación, como es el caso del artículo publicado en El Mundo: "¿Cuánto estás dispuesta a pagar?" y otras extrañas respuestas de un robot chino en su primera entrevista (EFE, 2017).

El caso de la robot Sophie es diferente y reviste un alcance mucho mayor puesto que, de entrada, tiene muchos más derechos que las mujeres en Arabia Saudí: goza de ciudadanía y pasaporte. Sophie es un modelo muy avanzado, con voz dulce, tez clara, rasgos caucásicos, y reflexiones de cierta profundidad. Habla del espíritu humano de superación, y llegó a afirmar que quería ser madre en una de sus intervenciones estelares. Todo un montaje de marketing que la convierte en una estrella mediática, desde la feminidad, pero que no es más que un imaginario proyectado, y muy bien proyectado, por sus programadores (Mígel, 2017). La multitud de artículos e imágenes que se difunden sobre ella nos transmiten imaginarios de inquietantes mundos del futuro. Según información de La Vanguardia:

Sophia Hanson concedió ayer por la mañana más de una docena de entrevistas y por la tarde participó en un mesa redonda sobre el futuro de la tecnología blockchain y de la inteligencia artificial. Todo dentro del Congreso mundial de la Internet de las cosas que se celebra hasta hoy en la Fira de Barcelona. Es de los primeros robots capaces de mantener una conversación con una persona de forma más o menos autónoma y con cierta interacción y empatía. (Molins, 2017).

Las entrevistas se reproducen en los artículos anteriormente señalados y dan idea de la capacidad de interacción y sofisticación de la programación. En el momento de escribir este artículo, todavía se han sofisticado más dichas habilidades.

Adentrarnos en las robots humanoides, con imagen de mujer, claramente dentro del marco del binario de género, es entrar también en un debate que ocupa páginas y páginas de los periódicos, por ser un tema recurrente para el sensacionalismo, pero también por ser un tema de mercado que mueve ingentes cantidades de dinero. Se trata de las llamadas "robots sexuales" que, como antes afirmábamos, no deberían ser denominadas así, pues la sexualidad implica una relación entre seres 
Tajahuerce-Ángel I., y Franco, Yanna G. Periódicos españoles e información sobre robótica e inteligencia artificial: una aproximación a imaginarios y realidades

desde una perspectiva de género

humanos que aquí no se da y se está prestando a confusiones muy serias en conceptos, debido fundamentalmente a la escasa formación en sexualidad por parte de quienes escriben y de la formación de opinión de quienes leen, igual que ocurre con la perspectiva de género. Es mercado y es consumo lo que se está fomentando, es creación de una necesidad a partir de un negocio que mueve mucho dinero. Según El Mundo, ya facturaba 15.000 millones en 2017 (González, 2017); aunque, en opinión de Nuño Domíngues en un artículo publicado en El País, disponemos todavía de pocos datos para poder predecir cómo será nuestro futuro sexual con los robots (Domínguez, 2017).

El Seminario de Investigación sobre Biotecnología, bioética, robótica y simulaciones desde una perspectiva de género y de la comunicación, del Instituto de Investigaciones Feministas y de la Facultad de Ciencias de la Información de la Universidad Complutense de Madrid, inició ya hace dos años investigaciones sobre esta materia, publicando dos artículos pioneros sobre estas y otras cuestiones vinculadas a la tecnología patriarcal y el interés del mercado en perpetuar los estereotipos de género (Tajahuerce \& Mateos, 2016 y Tajahuerce; Mateos \& Melero, 2017). Desde entonces se han venido desarrollando diversas investigaciones en esta línea. Uno de los problemas que encontramos es que, mientras se apuesta cada vez más decididamente por políticas abolicionistas en el ámbito de la prostitución, se abrió el primer prostíbulo con muñecas en Barcelona y de ello daba noticia La Vanguardia, resaltando que "la empresa asegura que es el primer servicio de estas características en Europa. Ofertan cuatro tipos de muñecas de distintas razas" (La Vanguardia Redacción Barcelona, 2017). La empresa promete una experiencia "realista y sin límites". El artículo del citado medio de Barcelona narra con detalle el ambiente, realista y humanizado, sin incluir ninguna perspectiva crítica ni reflexión sobre la prostitución desde la perspectiva de la violencia masculina que conlleva:

Katy espera en el interior. Sentada en el borde de la cama observa con sus ojos azules el horizonte, no importa que el horizonte acabe a medio metro, en una pared decorada con una reproducción de Klimt: 'El beso'. Sus descomunales pechos no precisan de sostén alguno para desafiar la ley de la gravedad, pero un sentido estético de las cosas impone que lleve sujetador, uno diminuto, muchas tallas más pequeño que el que seguramente se pone cuando va al supermercado. Pelo rubio, dedos finos, uñas postizas. El mobiliario incluye un armario, dos mesitas, un sillón y un televisor con canales X. La cortesía de la casa la representan una copa de cava y una pequeña porción de fresas. (Bernal, 2017).

Es lo habitual en esos imaginarios de sexualidad masculina que se mantiene en todas las informaciones, que son muchas, sobre los robots sexuales. Cuerpos construidos desde los estereotipos de la industria pornográfica, serviles, obedientes, aunque se puedan programar para que no lo sean. El cuerpo de las mujeres reales o construidas al servicio de los varones, manteniendo y difundiendo, aun en tono de sarcasmo muchas veces un constructo que legitima el sexo al servicio del placer masculino. 
Tajahuerce-Ángel I., y Franco, Yanna G. Periódicos españoles e información sobre robótica e inteligencia artificial: una aproximación a imaginarios y realidades

desde una perspectiva de género

Algunos periódicos son más sensacionalistas que otros a la hora de abordar el tema del "sexo" con robots, pero todos lo ven como una industria en expansión y rara vez se aborda desde un punto de vista de género, ni siquiera planteando "el juego" como elemento prioritario en su desarrollo, sino que se habla de "sexo" y "sexualidad", deformando conceptos.

Los artículos son críticos cuando se refieren a estudios realizados sobre esta cuestión, pero no lo son respecto al fenómeno en sí, en la mayoría de los casos y, además, son generalmente sensacionalistas, buscando titulares importantes acompañados de imágenes de silicona humanizada. La Vanguardia plantea en un titular si el sexo con robots es infidelidad, un titular muy sensacionalista que no concuerda exactamente con el contenido del artículo, en el cual a partir de una encuesta sobre si se considera o no infidelidad el sexo con robots, se profundiza en la inevitabilidad de la cuestión ya que los avances son muy rápidos:

El año pasado, el experto en nanotecnología Sergi Santos ya presentó Samantha, una muñeca dotada de un potente algoritmo y sensores que responde al tacto e interactúa con su propietario tanto en modo familiar haciéndole compañía en el sofá, por ejemplo- como en modo sexual, pudiendo, según su diseñador, llegar al orgasmo. (Rius, 2018).

Esta cuestión está también presente en la promoción y publicidad de estas máquinas que se ofertan perpetuando valores morales establecidos. En dicho artículo se cita a varios expertos y expertas para intentar ofrecer una opinión sobre la cuestión de si es o no recomendable el "sexo" con robots. Llama mucho la atención que, como ya hemos manifestado, no se incorporen los debates sobre qué es sexo, qué es la sexualidad humana, y las diferencias entre "sexo" y "placer", dando por sentada la realidad de que con los robots se mantienen relaciones sexuales. Por otro lado, la imagen de actrices pornográficas de las robots no se cuestiona, como no se cuestiona el imaginario masculino sobre lo que es o no una mujer y una relación afectiva, aunque sí se hable y se incorpore la opinión de un experto sobre la afectividad:

A este respecto, Vallverdú plantea que un robot sexual bien diseñado haría lo que su propietario quiera, cuando quiera y sin discusión, podría incorporar sensores para percibir el pulso, la temperatura y otros parámetros y con ellos diseñar su estrategia sexual, de modo que su capacidad de adaptación sexual superaría la de cualquier humano; pero ¿queremos eso? ¿Queremos banalizar así la sexualidad? ¿Qué pasa con la afectividad? (Rius, 2018).

Reflexiones en las que no se incorpora la perspectiva de género aun cuando en el inicio del artículo se cite una encuesta y se desagreguen los datos por sexos: pero sólo para referirse a la "fidelidad o infidelidad" (Rius, 2018). La "normalización" del deseo sexual masculino y del servicio a ese deseo sexual se mantiene en prácticamente todos los artículos sobre robots sexuales, incrementándose con las imágenes estereotipadas de las mujeres objeto de deseo sexual por parte de los varones y totalmente alejadas de la "naturaleza" femenina. 
Tajahuerce-Ángel I., y Franco, Yanna G. Periódicos españoles e información sobre robótica e inteligencia artificial: una aproximación a imaginarios y realidades

desde una perspectiva de género

El sensacionalismo llega a titulares como el de El Mundo: "James, el hombre que se acuesta, pasea y cena en restaurantes con su muñeca sexual... con el beneplácito de su mujer". (Bermejo, 2018). Los comentarios del artículo son muy significativos porque están cargados de estereotipos patriarcales:

Lo más llamativo de esta historia es que todos y cada uno de los encuentros que disfrutan James y April se llevan a cabo con el conocimiento y la aprobación de su mujer, a quien durante un tiempo costó, y mucho, asumir que había "otra" en su matrimonio. Teniendo en cuenta que su marido empezó a tener escarceos extramatrimoniales con April cuando ella tuvo que descuidar sus "obligaciones maritales" y dedicarse en cuerpo y alma a cuidar de su madre enferma, llegó a la conclusión de que lo mejor era llegar a un "acuerdo" para que su esposo no se sintiese "solo". (Bermejo, 2018).

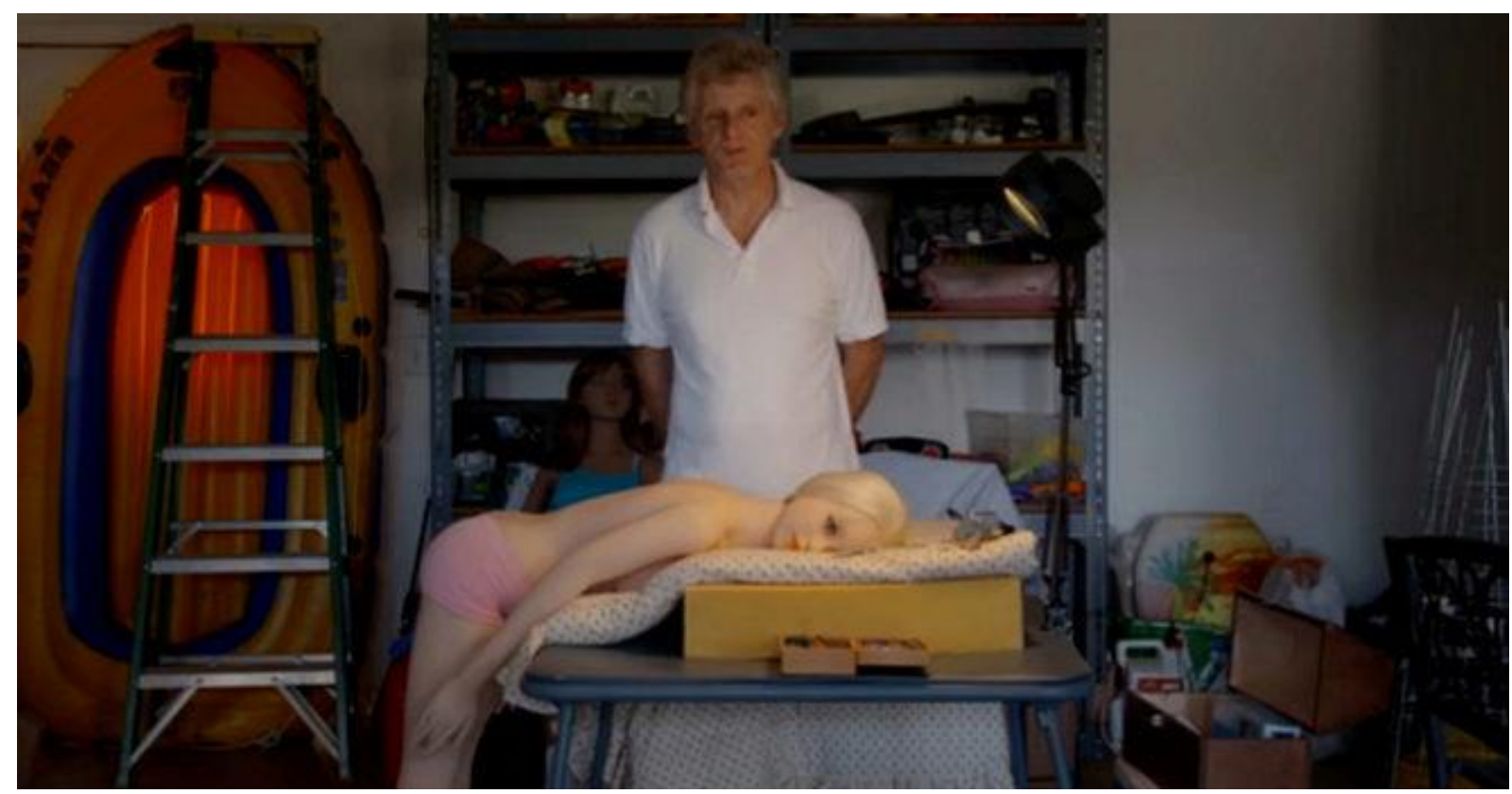

Figura 2: James junto a su muñeca April. "James, el hombre que se acuesta, pasea y cena en restaurantes con su muñeca sexual... con el beneplácito de su mujer". (Bermejo, 2018).

No hemos querido en esta primera aproximación al tema adentrarnos en otro de los aspectos de la robótica que ocupa muchas páginas en los periódicos estudiados: el empleo, en el cual tampoco se incorpora la perspectiva de género, ni tampoco la de la clase social o la de la etnia o el origen geográfico. Ello, a pesar de que sí es objeto del estudio citado al inicio y que será tema de análisis en posteriores trabajos de difusión de los resultados del mismo.

\section{CONCLUSIONES}

La ciencia y la tecnología no son neutras, conllevan una fuerte carga política, social y económica e ideológicamente contribuyen a construir mundos más adecuados para el ser humano o lo contrario. Por otro lado, la escasa formación con 
Tajahuerce-Ángel I., y Franco, Yanna G. Periódicos españoles e información sobre robótica e inteligencia artificial: una aproximación a imaginarios y realidades

desde una perspectiva de género

perspectiva de género en todos los niveles de responsabilidad de las y los profesionales de la información periodística, contribuye a que no se detecten los estereotipos de género en los productos que se distribuyen y presentan en Congresos, Ferias Internacionales, Seminarios de Investigación y Centros de Investigación. La relación, además, que construyen con los imaginarios de la cienciaficción refuerzan los valores patriarcales de los imaginarios de futuro que construyen. Las y los profesionales de la comunicación, como el resto de la sociedad han sido socializadas y socializados en una estructura concreta, por lo cual no pueden realizar un análisis sin sesgo de género. En este sentido se observa una clara diferencia en las informaciones con análisis feminista de las que no lo incluyen.

Los estudios de ingeniería no incorporan tampoco la perspectiva de género, por lo cual reproducen sin filtro crítico exactamente la misma visión que existe en la sociedad. Los casos más evidentes son aquellos en los que la información suministrada genera comportamientos radicales en las inteligencias artificiales. En ese caso los resultados se pueden contrastar muy claramente, pero no ocurre lo mismo con la creación de plataformas robóticas muy estereotipadas cuando se trata de fuerza, poder, deporte, etc., reforzando el valor que se da a lo masculino es espacios relevantes.

Por otro lado, se mantiene el mercado del llamado "sexo" que pasa de mujeres reales a mujeres construidas desde los mismos imaginarios de poder y sometimiento. Los periódicos analizados no suelen abrir debates vinculados a cómo se perpetúa un mercado y unos comportamientos masculinos que no rompen con su tradición de poder, ni siquiera en el encuentro con la máquina. La superficialidad de la prensa a la hora de escribir titulares y profundizar en nuevas realidades de la relación máquina-hombre (reforzando aquí el término "hombre") frente a nuevas interacciones tecnológicas, pone de relieve que se mantiene intacta la relación de poder y de control del varón sobre la sociedad del futuro.

La formación en género y en cultura científica para la ciudadanía y para las y los profesionales de los medios de comunicación, favorecerán la construcción de una cultura tecnológica que apueste por una sociedad más justa y equitativa que supere el binarismo de género y de paso a nuevas relaciones que permitan superar modelos obsoletos pero que se refuerzan en el mercado creando necesidades para impedir el avance en la igualdad. Ello va contra la propia ciencia que debe dar un salto hacia otros modelos para lograr una integración real del $100 \%$ de la población. No se puede hacer ciencia sin mujeres ni se puede hacer tecnología contra las mujeres. Defender imaginarios de prostitución, por ejemplo, cuando los gobiernos más progresistas y avanzados en políticas de igualdad apuestan claramente por la abolición, es, además de retrogrado, contrario al desarrollo. Construir prototipos robóticos que exaltan el binarismo de género, con mujeres dulces, suaves, y estereotipadas, que ni siquiera se ajustan a una realidad, sino que se imponen en el estereotipo, es cerrar oportunidades para la evolución hacia lo cyborg y la mejora del ser humano, con conceptos evolucionados de posthumanismo. 
Tajahuerce-Ángel I., y Franco, Yanna G. Periódicos españoles e información sobre robótica e inteligencia artificial: una aproximación a imaginarios y realidades

desde una perspectiva de género

\section{REFERENCIAS}

\subsection{Bibliografía científica}

Bozkurta, V; Tartanoglub, S. \& Dawes, G. (2015). Masculinity and Violence: Sex Roles and Violence Endorsement among University Students. Procedia. Social and Behavioral Sciences, 205, 254-260. doi: 10.1016/j.sbspro.2015.09.072.

Braidotti, R. (2015). Lo Posthumano. Barcelona: Gedisa.

Braidotti, Rosi (2009). Transposiciones: sobre la ética nómada. Barcelona: Gedisa.

Facchina, F. (2017). Sex robots: the irreplaceable value of humanity, BMJ, 358. doi: https://doi.org/10.1136/bmj.j3790.

González Fernández, A. (2017). Estudio del lenguaje sexista en los medios de comunicación a través de big data, Pragmalingüística, 25, 211-231.

Guerrero Salazar, S. (2007). Alternativas al lenguaje sexista de los medios de comunicación. Novedades legislativas y otras actuaciones, en Loscertales, F. \& Núñez, T. (Coords.), La mirada de las mujeres en la sociedad de la información (pp. 309-326). Madrid: Siranda Editorial.

Haraway, Donna (1984). Manifiesto Ciborg. El sueño irónico de un lenguaje común para las mujeres en el circuito integrado. Traducción de Manuel Talens con pequeños cambios de David Ugarte. Recuperado de https://dpya.org/wiki/index.php/Archivo:Manifiesto ciborg.pdf

López García, A. \& Morant Marco, R. (1991). Gramática femenina. Madrid: Cátedra.

Lozano Domingo, I. (1995). Lenguaje femenino, lenguaje masculino. Madrid: Minerva.

Márquez, M. (2013). Género gramatical y discurso sexista. Madrid: Síntesis.

Sullins, J. P. (2012). Robots, Love, and Sex: The Ethics of Building a Love Machine. IEEE Transactions on affective computing, 3(4). 398-409. doi: 10.1109/TAFFC.2012.31.

Tajahuerce, I.; Mateos, C. \& Melero, R. (2017). Análisis feminista de las propuestas pos humanas de la tecnología patriarcal. Chasqui. Revista Latinoamericana de Comunicación, 135, 123-141. doi: http://dx.doi.org/10.16921/chasqui.v0i135.3193.

Tajahuerce, I. \& Mateos, C. (2016). Simulaciones sexo genéricas, bebés reborn y muñecas eróticas hiperrealistas. Revista Opción. Universidad de Zulia, 32(81), 189-212. Recuperado de http://www.redalyc.org/articulo.oa?id=31048807010 
Tajahuerce-Ángel I., y Franco, Yanna G. Periódicos españoles e información sobre robótica e inteligencia artificial: una aproximación a imaginarios y realidades

desde una perspectiva de género

\subsection{Artículos periodísticos (por orden de citación en el texto)}

El País (2018, enero 13). Los robots llegan a las cocinas indias. Edición digital del diario El País. Recuperado de https://elpais.com/internacional/2017/12/20/mundo_global/1513775291_951068. html

Muela, D. (2017, octubre 18). Estados Unidos doblega a Japón en el primer combate real entre robots gigantes. Edición digital del diario El País. Recuperado de https://elpais.com/internacional/2017/10/18/mundo_global/1508338334_914412. html

Rubio, I. (2017, diciembre 15). ¿Será el próximo Shakespeare un robot? Edición digital del diario El País. Recuperado de https://elpais.com/tecnologia/2017/11/27/actualidad/1511784138_994343.html

Pinto, T. (2017, abril 13). Una Inteligencia Artificial se vuelve racista y machista al aprender a leer. diario.es. Recuperado de https://www.eldiario.es/tecnologia/Inteligencia_Artificial-sexismoracismo_0_632387552.html

Rius, M. (2017, octubre 24). Así es como la inteligencia artificial te puede star discriminando. Edición digital del diario La Vanguardia. Recuperado de https://www.lavanguardia.com/vida/20171024/432320320392/inteligenciaartificial-sexismo-racismo-discriminacion.html.

Mulet, J. M. (2016, abril 17). El hombre y la tecnología. Edición digital de El País. Recuperado de https://elpais.com/elpais/2016/04/17/eps/1460844052_146084.html.

Fernández Aguirre, A. (2017, diciembre 20). Robots. Edición digital de El País. Recuperado de https://elpais.com/elpais/2017/12/19/opinion/1513704642_526037.html.

El Mundo (2017). Las inteligencias artificiales tienen un poquito de instinto asesino. Edición digital del diario El Mundo. Recuperado de https://www.elmundo.es/tecnologia/2017/02/13/58a17adf46163f15698b4627.ht $\mathrm{ml}$

Oliveira, J. (2017, mayo 26). Un 'robocop' español se une a la policía de Dubái Edición digital del diario El País. Recuperado de https://elpais.com/tecnologia/2017/05/25/actualidad/1495704315_118401.html

Redacción La Vanguardia (2016, abril 15). China desvela su primer robot interactivo, la "diosa" Jia Jia. Edición digital del diario La Vanguardia. Recuperado de https://www.lavanguardia.com/vida/20160415/401129771303/china-desvelasu-primer-robot-interactivo-la-diosa-jia-jia.html 
Tajahuerce-Ángel I., y Franco, Yanna G. Periódicos españoles e información sobre robótica e inteligencia artificial: una aproximación a imaginarios y realidades

desde una perspectiva de género

EFE, (2017, abril 24). "¿Cuánto estás dispuesta a pagar?" y otras extrañas respuestas de un robot chino en su primera entrevista. Edición digital del diario El Mundo. Recuperado de https://www.elmundo.es/tecnologia/2017/04/24/58fde613468aeba2558b45b7.ht $\mathrm{ml}$.

Mígel, A. (2017, diciembre 11). Sophia, la robot más avanzada del mundo. Edición digital del diario El País. Recuperado de https://elfuturoesapasionante.elpais.com/sophia-la-robot-mas-avanzada-delmundo/

Molins, A. (2017, octubre 5). Sophia Hanson, humanoide: "Los sentimientos son innecesarios". Edición digital del diario La Vanguardia. Recuperado de https://www.lavanguardia.com/tecnologia/20171005/431798323694/sophiahanson-humanoide.html

González, S. (2017, junio 11). Sexo con robots, un sector que ya factura más de 15.000 millones. Edición digital del diario El Mundo. Recuperado de https://www.elmundo.es/f5/comparte/2017/06/11/59398852468aeb51638b45a5. html

Domínguez, N. (2017, julio 6). Así será nuestro futuro sexual con los robots. Edición digital del diario El País. Recuperado de https://elpais.com/elpais/2017/07/04/ciencia/1499198579_854901.html.

La Vanguardia Redacción Barcelona (2017, marzo 1). Abre en Barcelona el primer 'prostíbulo' de muñecas. Edición digital del diario La Vanguardia. Recuperado de https://www.lavanguardia.com/local/barcelona/20170301/42415172399/prostibul o-munecas-barcelona.html

Bernal, M. (2017, marzo 8). El burdel de las muñecas. Edición digital de El Periódico. Recuperado de https://www.elperiodico.com/es/sociedad/20170307/visita-nuevoburdel-munecas-barcelona-lumidolls-katy-5882857

Rius, M. (2018, mayo 13). ¿El sexo con robots es infidelidad? Edición digital del diario La Vanguardia. Recuperado de https://www.lavanguardia.com/vida/20180513/443536310487/sexo-robotsinfidelidad-munecas.html

Bermejo, D. (2018, enero 21). James, el hombre que se acuesta, pasea y cena en restaurantes con su muñeca sexual... con el beneplácito de su mujer. Edición digital del diario El Mundo. Recuperado de https://www.elmundo.es/f5/comparte/2018/01/21/5a62159922601ddb4a8b457c. html 
Tajahuerce-Ángel I., y Franco, Yanna G. Periódicos españoles e información sobre robótica e inteligencia artificial: una aproximación a imaginarios y realidades

desde una perspectiva de género

\section{AUTORAS:}

\section{Isabel Tajahuerce-Ángel}

Doctora en Ciencias de la Información. Profesora del Departamento de Periodismo y Comunicación Global de la Facultad de Ciencias de la Información de la Universidad Complutense. Experta en Comunicación y género. Directora del Seminario de Investigación sobre bioética, biotecnología, robótica y simulaciones desde una perspectiva de género y de la comunicación.

http://www.ucm.es/investigacionsobrebiotecnologiabioeticaroboticaysimulaciones/

isabeltj@ccinf.ucm.es

Orcid ID: https://orcid.org/0000-0001-8706-3992

\section{Yanna G. Franco}

Doctora en Derecho (Análisis económico del derecho y las instituciones). Profesora del Departamento de Economía Aplicada, Pública y Política de la Facultad de Ciencias de la Información de la Universidad Complutense. Directora del II Foro de robótica e IA con perspectiva de género: Sexualidad y tecnología. Directora de la Revista Comunicación y Género.

https://revistas.ucm.es/index.php/CGEN

ygfranco@ucm.es

Orcid ID: https://orcid.org/0000-0002-7175-5721

Researcher ID: K-9967-2017 